\title{
我国南方清洁地区春季地面 $\mathrm{O}_{3}$ 的某些特点 ${ }^{*}$
}

\author{
丁国安 汤 洁 房秀梅 吴 凡 符基萌
}

刘奇俊命香仡

(国家气象局气象科学研究院, 北京 100081)

苏维放宋文质

(中国科学院生态环境中心, 北京 100083)

\section{关链词 O、小时平均浓度、气温}

为了进一步搞清酸雨形成的大气物理化学机制, 我们分别于 1987 年 5 月1-24 日和 1989 年 5 月 25 日一 6 月 13 日在江西庐山进行了两次降水现场试验。观测点设在声山南䈋的电视 台 $(1400 \mathrm{~m})$ 、植物园 $(1100 \mathrm{~m})$ 、观音桥 $(70 \mathrm{~m})$, 三个观测点水平距离不大于 $5-6 \mathrm{~km}$, 它们都 是清洁点. 观测项目包括雨水、雾水、 $\mathrm{SO}_{2} 、 \mathrm{NO}_{n}$ 、气溶胶、 $\mathrm{O}_{3} 、 \mathrm{H}_{2} \mathrm{O}_{2}$ 以及气象参数. 有关雨 水化学组分的垂直分布以及高山云雾水的特点等将另文介绍”. 典型晴天、雨天 $O_{3}$ 浓度日变 化文献多有报道 ${ }^{[1,2]}$, 本文主要介绍春季多云金以及非晴天气象条件下的 $O_{3}$ 观测结果。

\section{一、资料}

两次降水试验中分别使用美国 Mornitor 实验室化学发光 Os 分析仪 Model 8410 和 美 国 Thermo Electron 紫外 $\mathrm{O}_{3}$ 仪 Model 49/49PS 直接测定地面 $\mathrm{O}_{3}$, 仪器使用前全部经过标 定. 第一次降水试验在三个点同时进行观测,第二次降水试验减少了植物园测点.

\section{二、结果与分析}

1. 全天有等时 O, 浓度全天有客时O 3 浓度低且没有有规则的日变化. 1989 年 6 月 8 日在电视台除了个别时间 $\left(5 、 6 、 18 、 19\right.$ 点)外几乎全天都有务但无雨, $\mathrm{O}_{3}$ 小时平均浓度十分 低, 其值都在 $16 \mathrm{ppb}$ 以下, $\mathrm{O}_{3}$ 浓度没有晴天午后通常所见到的增高特征, 日较差只有 $7 \mathrm{ppb}$ (见图 1a 实线). 由于第二次降水试验时遇到连续 9 天的客日, 当时天气形势是我国东部大 范围地区被变性高压控制, 卢山位于变性高压西南侧, 所以这些䙳多半为地形抬升及辐射形 成. 将这段时间观测到的 $\mathrm{O}_{3}$ 小时平均值求各小时平均 (见图 1a 虚线), 其反映出 $\mathrm{O}_{3}$ 的平 均日变化和 8 日这一天的 $\mathrm{O}_{3}$ 日变化是十分接近时, 而且其日较差更小一些 $(4 \mathrm{ppb})$. 而观测

本文 1990 年 5 月 14 日收到. 1990 年 9 月 6 日收到修改稿.

- 加㴓河的还有江祖凡、车太峰、姚扬苑、苏茂、周全、路洪荣等同志.

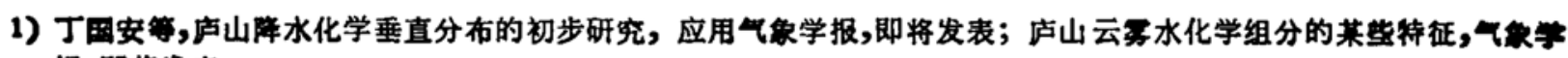
报, 即将发表。 
资料表明, 8 日这一天温度仍有明显的日变化,尽管振幅较小. 这就说明多票天气条件下由于 太阳耤射减弱从而不利于 $\mathrm{O}_{3}$ 产生.

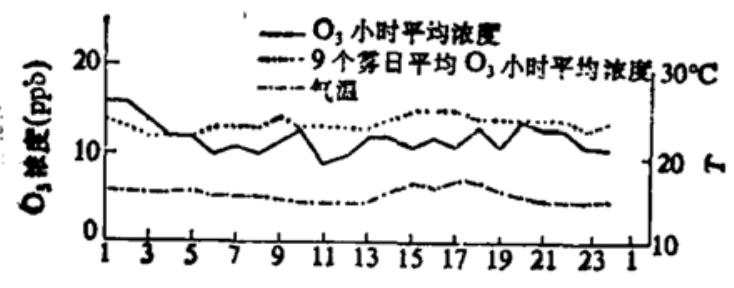

$\mathbf{8}$

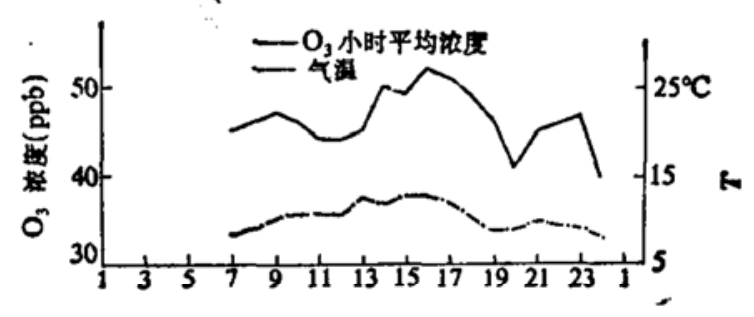

b

图 1

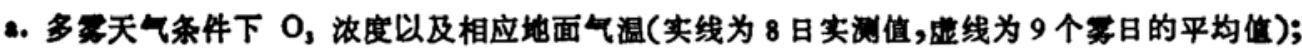

b. 多云间阴无家天气条件下 0 , 浓度及相应地面气温

2. 多云问阴无采天气的 $\mathrm{O}_{3}$ 这种天气条件下 $\mathrm{O}_{3}$ 日较差较有客时大. 1989 年 5 月 26 日电视台测点天空多云间阴 (以透光高积云为主), 14 时 15 分后部分时间出现高层云偶有零 星小雨, 全天无哥. 其小时平均 $\mathrm{O}_{3}$ 浓度是相同时间有客天气的 3 倍. 午后 $\mathrm{O}_{3}$ 浓度逐渐增 加, 16 时达到 $52 \mathrm{ppb}$, 而后逐渐下降. 虽然该天由于云量较多太阳辐射不很强烈, 和晴天相比 温度日较差较小, 但 $\mathrm{O}_{3}$ 日较差仍为有客天气时的两倍左右 (见图 1b). 另外, 各小时气温的 变化曲线和相应时段 $O_{3}$ 曲线配合较好, 而且温度日较差 ( $5^{\circ} \mathrm{C}$ 左右)也大于有客天气时的温 度日较差 ( $3^{\circ} \mathrm{C}$ 左右)。

3. 不同高度 $O_{3}$ 平均状况作者分别把两次观测期间山上及山下测点的日平均值、日 最小值、日最大值求出平均(表 1). 结果表明: 山下测点的各项平均值都比山上测点为大,特 别是日均值、日最大值的平均值.

表 11987 、1989 年两次降水试验期间,不同高度洞点各日的日均值、日最小值、日最大值 的平均值 (ppb)

\begin{tabular}{|c|c|c|c|c|}
\hline & 高度 (m) & 日均值 & 日最小值 & 日最大值 \\
\hline 电视台 & 1400 & 22 & 18 & 28 \\
\hline 观音挢 & 70 & 27 & 19 & 35 \\
\hline
\end{tabular}

这种差别与两个测点所处的局地气象条件有关. 因为庐山地区降水多水汽丰沛, 除了有 天气过程时山头时常被云笼罩外,即使晴天白天仍有沿山坡、山谷上升的湿空气在山体上部 冷成云形成云客环绕之势. 而山下测点仅在有降水天气过程的前后出现阴雨, 极少有云等 天气的出现. 所以山上的务日和等持续时间都大于山脚. 据统计, 观测期间山上测点等日为 30 天,占总观测天数的 $70 \%$ 左右, 而山下无雾日. 明显地, 在结果 1 中有客天气 $\mathrm{O}_{3}$ 浓度特 点将带入此节中. 因为山顶客日多所以在取平均值比较时, 山顶平均值更多地反映出雾天的 特点,这和结果 2 的分析结果也不矛盾.

关于这种差异可以 1987 年 5 月 7 日为例说明。该日为晴天, $O_{3}$ 记录从子夜开始到下午 终止(图 2)、观音桥的 $\mathrm{O}_{3}$ 浓度有较大的变化. 因为电视台没有同时段实测资料, 这里引用植 物园的资料. 同观音桥相比植物园 $\mathrm{O}_{3}$ 浓度变化就小得多. 原因在于该天虽是晴天, 观测期 间植物园测点仍处在阵阵随风飘来云蔡之中, 能见度依然不好, 光照很弱. 
声山地区 $\mathrm{O}_{3}$ 浓度接近于国外某些清洁点的水平 ${ }^{[3]}$.

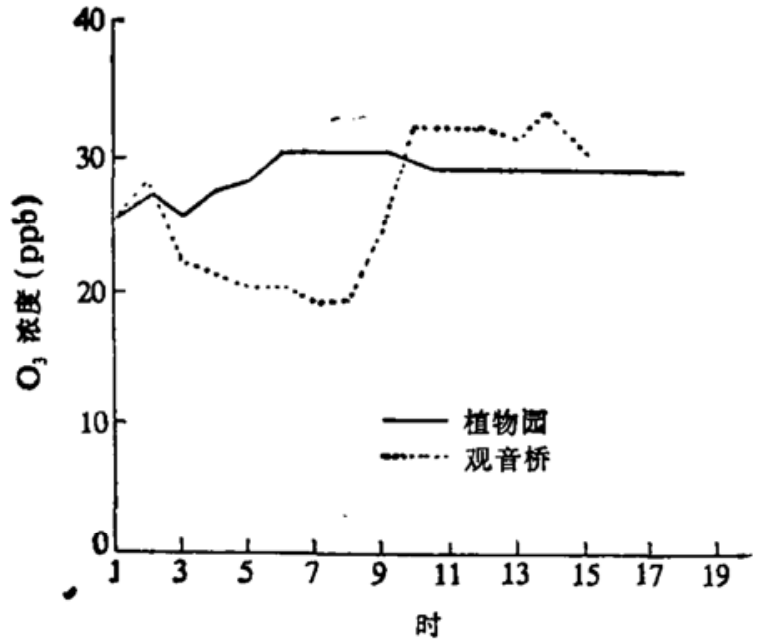

图 21987 年 5 月 7 日植物园、观音桥测点 O, 每小时证点瞬时浓度值

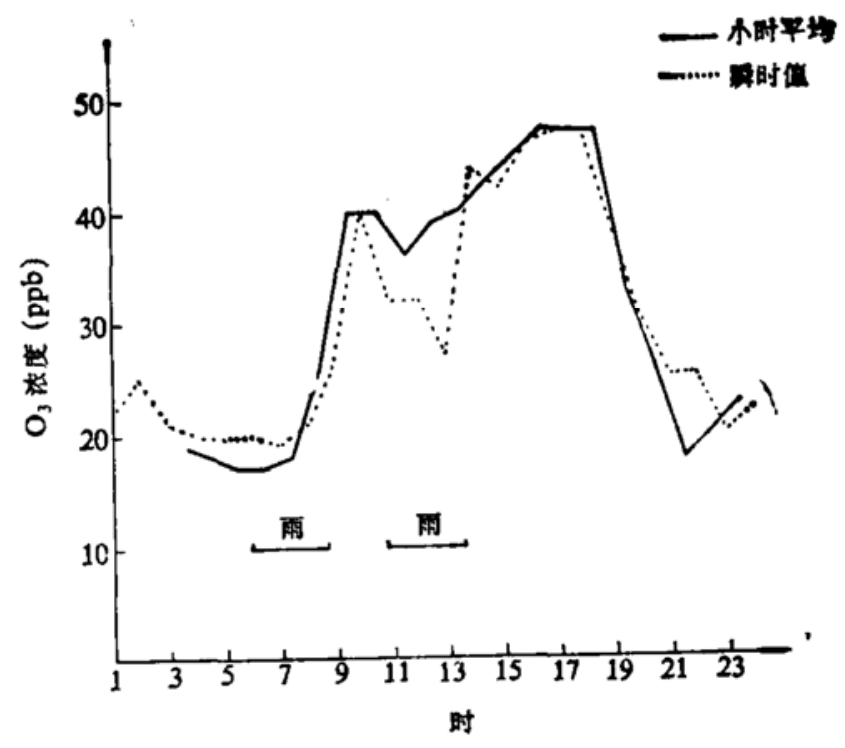

图 31987 年 5 月 6 日观音桥测点出现阵性 降水时 $\mathrm{O}$, 浓度

小时 $\mathrm{O}$, 浓度平均值点在 $30 \mathrm{~min}$ 位量上

4. 阵性降水的影响 1987 年 5 月 6 日白天除了 5 时 50 分- 8 时 40 分、 10 时 40 分一 13 时 40 分两段时间有阵性降水外, 其余多云间阴. 图 3 中实线表示的是观音桥测点该日逐 时 $\mathrm{O}_{3}$ 小时平均值, 从图中可以看出对应这两段阵雨, $\mathrm{O}_{3}$ 浓度出现低值. 第一段降水时间出 现已是日出之后,但它比夜间的 $\mathrm{O}_{3}$ 浓度值 $(25 \mathrm{ppb})$ 还要低 $3 \mathrm{ppb}$. 第二段阵性降水,其间 $\mathrm{O}_{3}$, 最低值 (36ppb) 比此段时间的开始值 $(40 \mathrm{ppb})$ 低大约 $4 \mathrm{ppb}$. 而如果按正常 $\mathrm{O}_{3}$ 日变化规 律,应该有相反的结果. 由此表明白天降水将降低地面 $\mathrm{O}_{3}$ 浓度. 图 3 中虚线表示的是同日 每小时正点 $\mathrm{O}_{3}$ 瞵时浓度变化曲线, 其对应于阵雨有更显著的两谷特征。

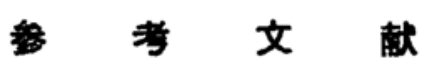

[1] Garland. J.A. et al., Quart. J.R. Met. Soc.. 105(1979), 169-183

(2) Muralidharan, V. et al.. PAGEOPH, 130 (1989), 1:47-55.

(3) Robinson, E. et al., Reviews of Geophysics, 26(1988), 1:63-80 